\title{
Microplastic Pollution in Surface Waters of Urban Watersheds in Central Texas, United States: A Comparison of Sites With and Without Treated Wastewater Effluent
}

OPEN ACCESS

Edited by:

Javier Hernández-Borges, University of La Laguna, Spain

Reviewed by:

Miguel Ángel González-Curbelo, EAN University, Colombia Miguel Gonzalez-Pleiter, Autonomous University of Madrid, Spain

${ }^{*}$ Correspondence:

Susan Power Bratton Susan_Bratton@Baylor.edu

${ }^{\dagger}$ Present address: Department of Biology,

Baylor University, Waco, TX United States.

Specialty section: This article was submitted to Environmental Analysis, a section of the journal Frontiers in Analytical Science

Received: 19 January 2022 Accepted: 28 January 2022 Published: 17 February 2022

Citation:

Stovall JK and Bratton SP (2022) Microplastic Pollution in Surface Waters of Urban Watersheds in Central Texas, United States: A Comparison of Sites With and Without Treated Wastewater Effluent.

Front. Anal. Sci. 2:857694. doi: 10.3389/frans.2022.857694

\author{
Jasmine K. Stovall ${ }^{\dagger}$ and Susan Power Bratton * \\ Department of Environmental Science, Baylor University, Waco, TX, United States
}

Most studies of microplastics in freshwater have investigated presence in creeks and rivers below sewage effluents and storm drains. This study examines microplastic distribution in surface waters, including springs and primary streams, located within small, urban Karst watersheds, with and without sources of wastewater treatment discharge. Study locales were in Texas, United States, either in Waco on the Brazos River or in or downstream from San Marcos on the San Marcos River. Research teams collected $800 \mathrm{ml}$ surface water from four different small watersheds and an urban pond $(n=779)$ and filtered them through $53 \mu \mathrm{m}$ Nitex mesh. Teams collected samples from springs or primary streams to the lower end of creeks and across stream transects based on distance from the bank and the presence of vegetation and debris. Teams also replicated samples seasonally. Stereo microscopy examined each filter for microplastic particles and subsequently color and type (i.e., fragment, fiber, or sphere). Additionally, we analyzed the influence of urbanization and land use on the origin and transport of the microplastics. Overall, the filters recovered 1,198 microplastic fibers and fragments. On average, $56.7 \%$ of all samples at each study locale contained microplastics. Particle abundance was the highest at Proctor Springs $(\bar{x}=3.38)$ and lowest at the pond $(\bar{x}=0.98)$, both headwaters. Local human use and runoff were thus potentially important factors in microplastic presence, while sewage discharge was not unilaterally the primary determinant of microplastic abundance. Peak pollution events occurred in June, September, and October, indicating seasonality of rainfall and recreation affected microplastic frequency and type.

Keywords: microplastics, aquatic systems, urban watersheds, karst watersheds, sewage effluent, urban springs, urban pollution

\section{INTRODUCTION}

Since the early 1950's, plastic production has markedly increased on a global scale (Dris et al., 2015a; Geyer et al., 2017). The convenience, durability and versatile nature of this synthetic polymer have contributed to an increase in its use and subsequently, post-consumer plastic waste. In 2012, 288 million tons of plastic were produced globally, consisting largely of single use containers and packaging products (Jambeck et al., 2015). It is estimated that 80 percent of marine plastic pollution originates as land-based trash (Andrady, 2011). Evidence of such plastic waste has been widely 
documented in both marine (do Sul and Costa, 2014; Law and Thompson, 2014; Mathalon and Hill, 2014; Peeken et al., 2018) and freshwater (Dris et al., 2015a; Baldwin et al., 2016) systems worldwide (Barnes et al., 2009; Browne et al., 2011). Microplastics are synthetic polymeric particles less than $5 \mathrm{~mm}$ in size (Masura et al., 2015; Peters and Bratton, 2016). Microplastics can enter into aquatic systems via numerous pathways including, but not limited to improper waste management, agricultural and stormwater runoff, industrial waste effluent (Eerkes-Medrano et al., 2015), aerial transport (Allen et al., 2019), wastewater treatment plant effluent (Carr et al., 2016; Mason et al., 2016; Simon et al., 2018) and residential laundry effluent (Napper and Thompson, 2016; De Falco et al., 2018).

Previous studies suggest plastic transport from inland waters as a probable source of marine microplastic pollution (Thiel et al., 2013; Eerkes-Medrano et al., 2015; Lebreton et al., 2017). An estimated 1.15-2.41 million tons of plastic waste is transported from rivers to the ocean annually (Lebreton et al., 2017). Hence, microplastics in freshwater systems has been, and remains, a trending research topic. There are numerous studies in which microplastic pollution in lakes and rivers has been investigated and demonstrated (Li et al., 2020), however, few studies have been conducted within urban settings and other small watershed systems, specifically within the central Texas, United States region. Microplastic contamination in freshwater systems has been reported in lakes (Wang et al., 2018; Sighicelli et al., 2018), river and lake shore sediments (Jiang et al., 2018; Peng et al., 2018), rivers (Lahens et al., 2018; Kapp and Yeatman, 2018), as well as urban surface and wastewaters (Di and Wang, 2018; Yin et al., 2019). Additional findings suggest that increased urbanization and wastewater treatment plants serve as primary sources of microplastic pollution within freshwater systems (Schmidt et al., 2018; Talbot and Heejun, 2022). An investigation of a subtropical river in southern Africa, however, did not find a clear spatial distribution pattern of microplastics relative to a wastewater treatment plant (Dalu et al., 2021). A recent field sampling study of an urban creek in Illinois concluded that concentrations of microplastics in urban streams may be orders of magnitude greater than in larger rivers (Noseworthy et al., 2021). A modeling study by Meijer et al. (2021) found that more than 1,000 rivers were contributing significantly to oceanic plastic pollution, and that small urban rivers were among the greatest contributors to plastic transport in freshwater systems. However, many knowledge gaps pertaining to the characterization and abundance of microplastics and their associated sources of origin, fate and transport within freshwater systems remain.

The purpose of the present study was to assess and compare microplastic pollution levels in spring-fed and runoff-fed freshwater systems in highly urbanized, small watersheds with and without local point-source wastewater effluents. Additionally, we investigated general patterns in microplastic spatial distribution across sample sites within individual study locales as well as among different micro-habitat types within each study system. Finally, we evaluated the influences of seasonality, urbanization and land use type on the abundance, origin, and transport of microplastics within small watersheds. For the purposes of this research, microplastics were defined as "artificial polymers (e.g., polyester or nylon), and manufactured products (i.e., manufactured natural and nonnatural material), that range in size from 50 to $5,000 \mu \mathrm{m}$ " (Masura et al., 2015; Peters and Bratton, 2016). We hypothesized the following: 1) sample sites not containing local point source sewage effluent would have lower microplastic pollution levels than sample sites with local point source sewage effluent; 2) sites that are subjected to frequent occurrences of direct human contact via recreational use would have higher microplastic pollution levels than those sites that are geographically isolated in comparison, or not as accessible to high volume human recreational use and direct human contact; 3) systems fed by groundwater and/or springs would have fewer microplastic particles per sample, on average, than run-off fed systems and; 4) still water micro-habitats (e.g., pools and deposition bends), where microplastic particles have the potential to deposit, would have more microplastics per sample, on average, than running water micro-habitats (e.g., riffles).

\section{METHODS}

\section{Study Locales}

This research examined and compared microplastic pollution levels in the surface waters of five different freshwater systems, inclusive of two creeks, one spring, one pond and one river, with a total number of eighteen sample sites, consisting of varying water sources and degrees of urbanization across study locales (Table 1; Figures 1, 2). The selected study areas are located within the central Texas region in the cities of Waco and San Marcos, TX, which are geologically characterized by karst landscapes composed of limestone bedrock and spring fed urban creeks or rivers. Waco is in the Brazos River watershed. The sampling locales in Waco, including Proctor Springs, Wilson's Creek, Buena Vista Pond, and Waco Creek, are all upstream from any sewage effluents, except the mouth of Waco Creek (site WC1) at its confluence with the Brazos River. Due to a dam on the Brazos, water from the river, at point below upstream sources of treated wastewater backs into and mixes with the water at confluence with Waco Creek (Figure 1). The outfall from the Waco wastewater plant is downstream of the study sites. A high-volume constellation of springs, known as Aquarena Spring, form the headwaters of the San Marcos River, within the City of San Marcos. The city's wastewater plant releases treated effluent just upstream from the confluence of the San Marcos River and the Blanco River. Three of the study sites (SM1-3) on the San Marcos are downstream from the plant (Figure 2). All study locales and their respective sample sites were selected based on geographical and hydrological comparativeness relative to other study locales, accessibility, permissibility and were established to reflect the most accurate overall representation of the stream profile while also encompassing a variety of land use and types of development along each stream channel (e.g., commercial, recreational and residential). 
TABLE 1 | Study locales and general descriptive of sampling sequences and basic hydrology for each locale.

\begin{tabular}{|c|c|c|c|c|c|}
\hline $\begin{array}{l}\text { General } \\
\text { descriptive }\end{array}$ & $\begin{array}{c}\text { Waco creek } \\
\text { (WC)-Locale \#1 }\end{array}$ & $\begin{array}{l}\text { Wilson's creek } \\
\text { (WS)-Locale \#2 }\end{array}$ & $\begin{array}{l}\text { Proctor springs } \\
\text { (PS)-Locale \#3 }\end{array}$ & $\begin{array}{c}\text { Buena vista } \\
\text { pond (BV)-Locale } \\
\# 4\end{array}$ & $\begin{array}{c}\text { San marcos } \\
\text { river (SM) - Locale } \\
\# 5\end{array}$ \\
\hline Water Source & Run-off & $\begin{array}{l}\text { Run-off, low discharge } \\
\text { spring }\end{array}$ & Groundwater & Run-off & $\begin{array}{l}\text { High discharge spring } \\
\left(174 \mathrm{ft}^{3} / \mathrm{s}\right)\end{array}$ \\
\hline Catchment Size & $27.2 \mathrm{~km}^{2}$ & - & - & - & $1,352 \mathrm{~km}^{2}$ \\
\hline $\begin{array}{l}\text { No. of Sample } \\
\text { Sites }\end{array}$ & 6 & 2 & 3 & 1 & 6 \\
\hline $\begin{array}{l}\text { No. of Sampling } \\
\text { Intervals }\end{array}$ & 7 & 4 & 5 & 4 & 3 \\
\hline Sampling Dates & $\begin{array}{l}\text { Sept. 2017, Oct. 2017, Mar. 2018, } \\
\text { Apr. 2018, Jun. } 2018 \text { and Jul. } 2018\end{array}$ & $\begin{array}{l}\text { Jul. 2017, Mar. 2018, } \\
\text { Apr. } 2018 \text { and Jun. } 2018\end{array}$ & $\begin{array}{l}\text { Jul. 2017, Mar. 2018, Apr. } \\
\text { 2018, Jun. } 2018 \text { and Jul. } \\
2018\end{array}$ & $\begin{array}{l}\text { Jul. } 2017 \text {, Mar. 2018, Apr. } \\
2018 \text { and Jun. } 2018\end{array}$ & $\begin{array}{l}\text { Apr. 2018, Jun. } 2018 \\
\text { and Jul. } 2018\end{array}$ \\
\hline Land Use Type & $\begin{array}{l}\text { Commercial, Recreational, } \\
\text { Residential }\end{array}$ & Recreational & Recreational & Recreational, Residential & $\begin{array}{l}\text { Recreational, } \\
\text { Commercial }\end{array}$ \\
\hline
\end{tabular}

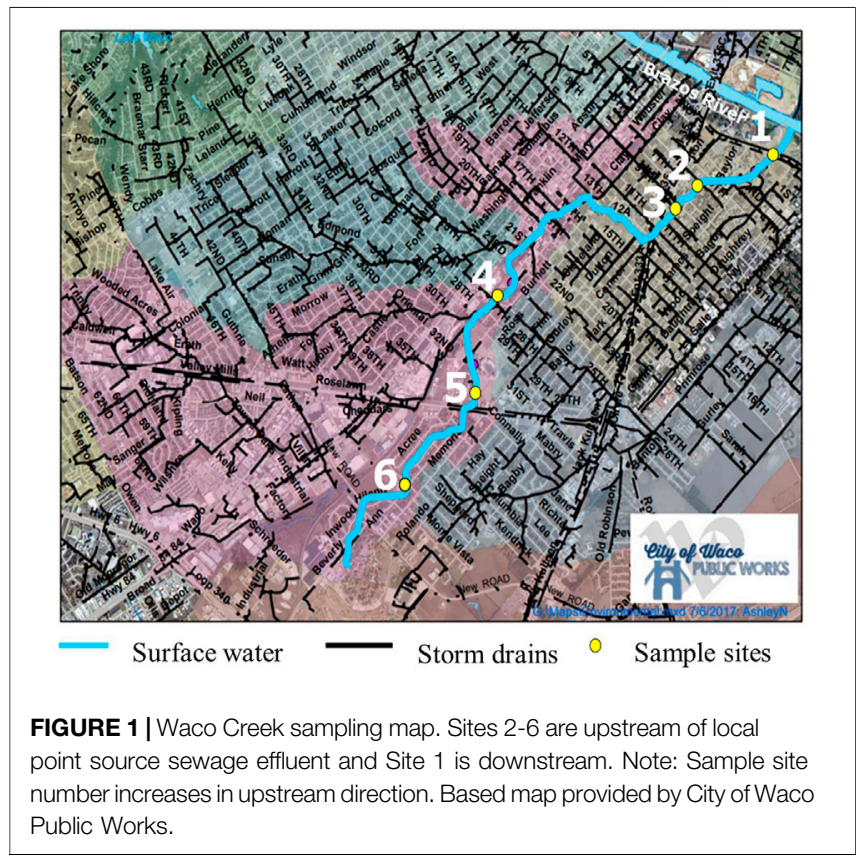

\section{Field Sampling Preparation and Collection Methods}

Between May 2017 and July 2018, the investigators collected a total of 779 surface water samples across the study locales (Table 1). All samples were collected along the stream gradient of each study locale, beginning at the furthest point downstream and moving in an upstream direction (Figures 1, 2). At each study locale, two replicates of surface water samples of $800 \mathrm{ml}$ each were collected from eight different micro-habitat types per sample site using long-handled steel dippers. The micro-habitat types examined were categorized as follows: riffle; pool; eroding bank; deposition bend (point bar); debris; open water 0.91 and $2.44 \mathrm{~m}$ from the bank; emergent vegetation; and well or seep (collected at Proctor Springs only). Surface water depth was generally defined as the top $0.07 \mathrm{~m}$ of the water column. However, there was some variation between study locales due to the shallow nature of some of the sample sites, particularly first order creeks and springs, in which the maximum depth was less than $0.07 \mathrm{~m}$. Immediately following collection, the water was filtered on-site through a $53 \mu \mathrm{m}$ Nitex nylon mesh filter on a $7.62 \mathrm{~cm}$ diameter wooden embroidery hoop into a $400 \mathrm{ml}$ glass beaker. Once filtered, the filter was covered with a $10.16 \mathrm{~cm}$ diameter glass round and sealed in aluminum foil to prevent contamination during handling and transport. The remaining filtrate in the beaker was discarded on site. The effects of rainfall events on microplastic pollution levels were not a part of this investigation, therefore, sample collection sequences were scheduled to intentionally avoid rain by at least a $48 \mathrm{~h}$ window, to collect as close to base flow conditions as possible.

\section{Laboratory Analysis}

All samples were removed from the foil wrapping upon return the laboratory to prevent mold, however, the glass rounds remained covering the filter to eliminate air contamination from the laboratory environment. Polymer identification and quantification protocol established by Hidalgo-Ruz et al. (2012) was used to visually analyze each filter for the presence of microplastics via a VWR stereomicroscope. Microplastics were extracted by hand via metal tweezers, transferred to a microscope slide and sealed with a glass cover slip. All natural fibers, such as cotton or wool, and all natural materials, such as grass, twigs, or insects, were excluded from the sample. Total microplastics extracted was enumerated per sample and each particle was characterized individually by particle form, color, and condition (i.e., frayed ends and body). Microplastic forms included fibers, spheres (or pellets), and fragments (HidalgoRuz et al., 2012). Microplastic color was characterized using the Munsell Color System, a three-dimensional color matching system that identifies colors by three attributes: hue, value and chroma (Peters et al., 2017). Hue defines major color families (e.g., red, green, blue), value measures the relative lightness or darkness of a color and chroma measures the intensity of a color.

Although these urban watershed samples have not yet been analyzed for chemical composition, the Bratton laboratory has conducted an analysis of materials collected utilizing the same visual methods and identification protocols in cooperation with a 


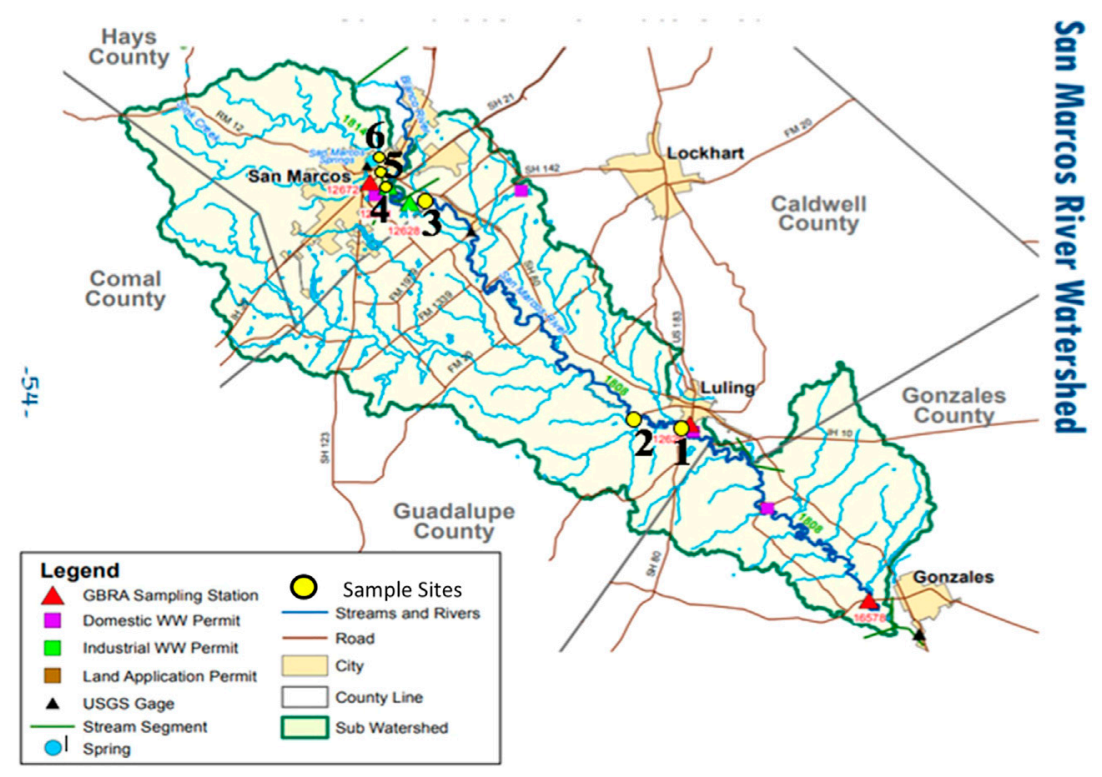

FIGURE 2 | San Marcos River watershed and sampling site map. Sites 1-3 are downstream from local point source sewage effluent and Sites 4-6 are upstream. Note: Sample site number increases in upstream direction, Base map provided by the Guadalupe-Blanco River Authority.

laboratory utilizing pyr/GC-MS instrumentation at the University of Minnesota Duluth (Peters et al., 2018). Samples were analyzed using an Agilent 7890B Gas Chromatograph with Agilent 5977A mass-selective detector (MSD) Mass Spectrometer and Gerstel Pyrolysis/Thermal Desorption Unit (Gerstel GmbH \& Co. KG, Germany). All pyrolyzer and GC unit parameters adhered to the protocol of Hendrickson et al. (2018). Although a significant proportion (41.8\%) remained "unknown" and some were likely of mixed composition (many of the unknowns produced petroleum-like chromatographs), all the identified particles were plastics or artificial polymers or resins. Materials detected included PVC, PET, and nylon. None of the analyzed particles or fibers were natural materials such as wood (see Peters et al.,. 2018).

\section{Quality Assurance and Quality Control (QA/QC)}

Contamination prevention measures were implemented throughout the entirety of this study. Blank filters were positioned in various locations around the laboratory and left exposed to the open air for $24 \mathrm{~h}$ to examine background contamination levels. Following the $24 \mathrm{~h}$ period, microplastic contamination of the blanks was observed via stereomicroscopy. After three rounds of testing blanks, visual microscopy revealed that greater than $10 \%$ of the blanks were contaminated with microplastics. As a result, the use of glass round covers was employed to minimize airborne background contamination from the hood and ventilation systems in the laboratory. Prior to sample collection, all filters, glass covers, and foil wrappings were triple rinsed with filtered, distilled, and deionized water and visually examined via microscopy to ensure the absence of contamination and stored covered until use. The research team examined samples of the distilled deionized water from the Baylor
University distillation plant and found no evidence of plastic or particle contamination. All filters were inspected regularly for frayed mesh and replaced as needed. The steel dippers, glass rounds and foil wrapping were triple rinsed in the water at the associated sample site prior to use. Water probes and beakers were rinsed in deionized water between sampling intervals. Lab benches and other work areas were cleaned regularly. The colors of each field assistant's clothing and shoes were recorded during each sampling event as a measure of cross-checking for contamination from the researchers. Samples were stored, transported, processed, and analyzed with glass covers on at all times, except for fiber extraction in which only small portions of the filter were exposed to air for small amounts of time. Any minor occurrences of contamination in the field from ambient air were considered part of the plastic present at the sample site.

\section{Statistical Analysis}

Statistical analyses were performed using non-parametric tests (i.e., Kruskall-Wallis and Mann-Whitney) and linear regressions via IBM SPSS Statistics for Windows, Version 23, to examine differences in microplastic abundance within and between study locales, sampling intervals, micro-habitat types, still vs. running water micro-habitats and with vs. without point source sewage effluent. The Community Analysis Program III by Pices Inc. was used to analyze similarities in particle hue across sample sites and sampling intervals. Statistical results $p<0.05$ are identified as significant and $p \leq 0.1$ are identified as trends.

\section{RESULTS}

In total, 1,198 microplastic particles were extracted from 779 samples (623.2 L) across all study locales (Table 1), inclusive of fibers (95.0\%) and fragments (5.0\%) (Figure 3). No beads, 


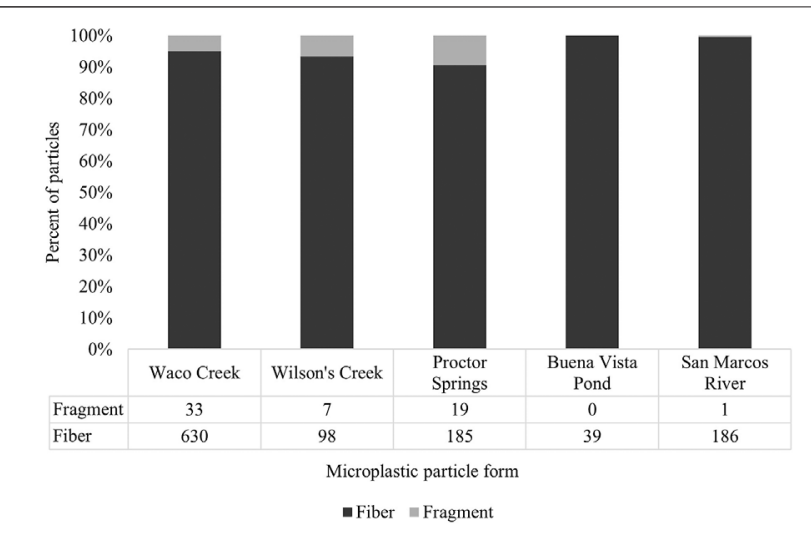

FIGURE 3 | Frequency and percent of microplastic particle forms recovered in samples across all study locales.

spheres, or pellets appeared in the samples. Approximately 57\% of all samples were contaminated with microplastics, on average, ranging from 33.3 to $80 \%$ of total samples contaminated across individual locales. While fibers were the most recovered microplastic form across study locales, fragments made up at least $5 \%$ of the total particle counts for Waco Creek (WC), Wilson's Creek (WS) and Proctor Springs (PS) (Figure 3).

\section{Microplastic Pollution Comparison of Sites With and Without Local Sewage Effluent}

Two of the five study locales, Waco Creek and San Marcos River, contained sample sites both upstream of and downstream from local point source sewage effluent. For the San Marcos River, the mean number of microplastics per sample was significantly higher in those sites upstream of the WWTP containing minimal to no sewage effluent $(\bar{x}=1.51)$, versus the sites downstream from the WWTP, which contain treated discharge $(\bar{x}=0.57)(p=0.011)$, where $\bar{x}=$ mean number of microplastics per sample. However, no such differences were found for Waco Creek $(p=0.342)$, where the mean number of microplastics per sample at sites upstream versus downstream from local sewage effluent were 1.62 and 1.35 , respectively.

\section{Microplastics Pollution Levels Across a Spatial Scale: A Spatial Distribution Comparison Between Sample Sites Within Individual Study Locales}

Of the five study locales sampled, only the San Marcos River yielded significant differences in mean number of microplastics per sample between sample sites $(p=0.040)$. Out of all six sampling sites along the river channel, site SM4 contained a significantly higher number of microplastics per sample in comparison to the other five sites (Table 1). At Waco Creek, we observed the pattern of a decrease in mean number of microplastics in the upstream direction for sites WC2-6 of Waco Creek, however, a linear regression yielded an $r^{2}=$ 0.5449 , indicating that there is no significant correlation between microplastic pollution levels and direction of flow (Site 1 was

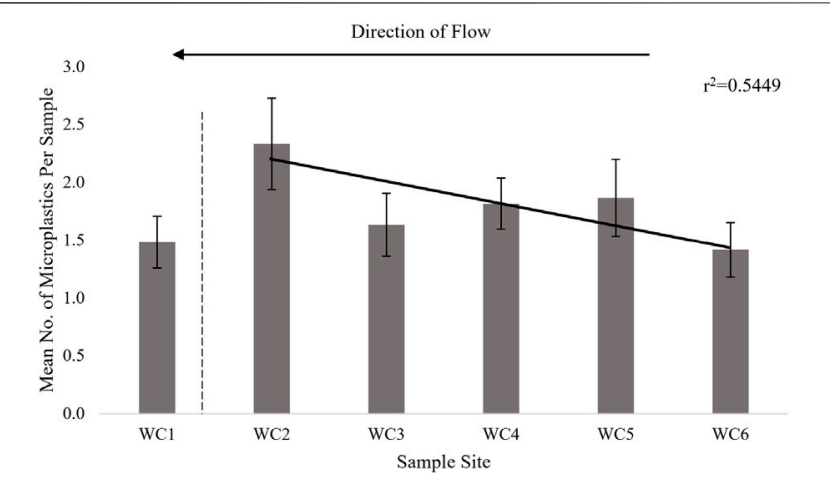

FIGURE 4 | Mean number of microplastics per sample at each Waco Creek sample site. The dotted line indicates the exclusion of WC1 from the regression analysis as it is part of Lake Brazos.

excluded from regression as it is a part of Lake Brazos, not Waco Creek, by definition) (Figure 4). No significant difference in mean microplastic counts was found between the sample sites along Waco Creek $(p=0.330)$. The opposite was found to be true in the case of the San Marcos River, where we observed a pattern of an increase in the mean number of microplastics in the upstream direction. However, a linear regression yielded an $r^{2}=0.3042$, indicating that there is no significant increase in microplastic pollution levels as you move upstream. No such significant relationships or similar patterns were observed for sample sites along Wilson's Creek, Proctor Springs or Buena Vista Pond $(p>0.05)$.

\section{Total Microplastic Pollution Levels: A Comparison Within and Across Study Locales}

Individual samples collected from all study locales most frequently contained between zero and three particles per sample, with at least $30 \%$ of all samples per study locale containing zero microplastics. The number of particles per sample across study locales ranged from a minimum of zero to a maximum of 73 particles per sample, which was found in a single sample at Proctor Springs and is undoubtedly an outlier within the data (Table 1). The study locales in order from overall most polluted to least polluted were as follows: Proctor Springs $(\bar{x}=3.38)$, Waco Creek $(\bar{x}=1.58)$, San Marcos River $(\bar{x}=1.54)$, Wilson's Creek $(\bar{x}=1.33)$ and Buena Vista Pond $(\bar{x}=0.98)$, where $\bar{x}=$ mean number of microplastics per sample. Relationships between microplastic abundance and both individual micro-habitat type and current (i.e., still vs. running water micro-habitats) were investigated. However, these relationships were not found to be significant $(p>0.05)$.

With a total count of 204 microplastics and an average of 3.38 microplastics per sample, Proctor Springs contained significantly higher levels of microplastics in total $(p=0.000)$ and per sample, on average $(p=0.000)$, despite its position as the point of origin for an urban stream. Aside from Proctor Springs, the remaining four study locales contained approximately 1 microplastic per sample, on average. 


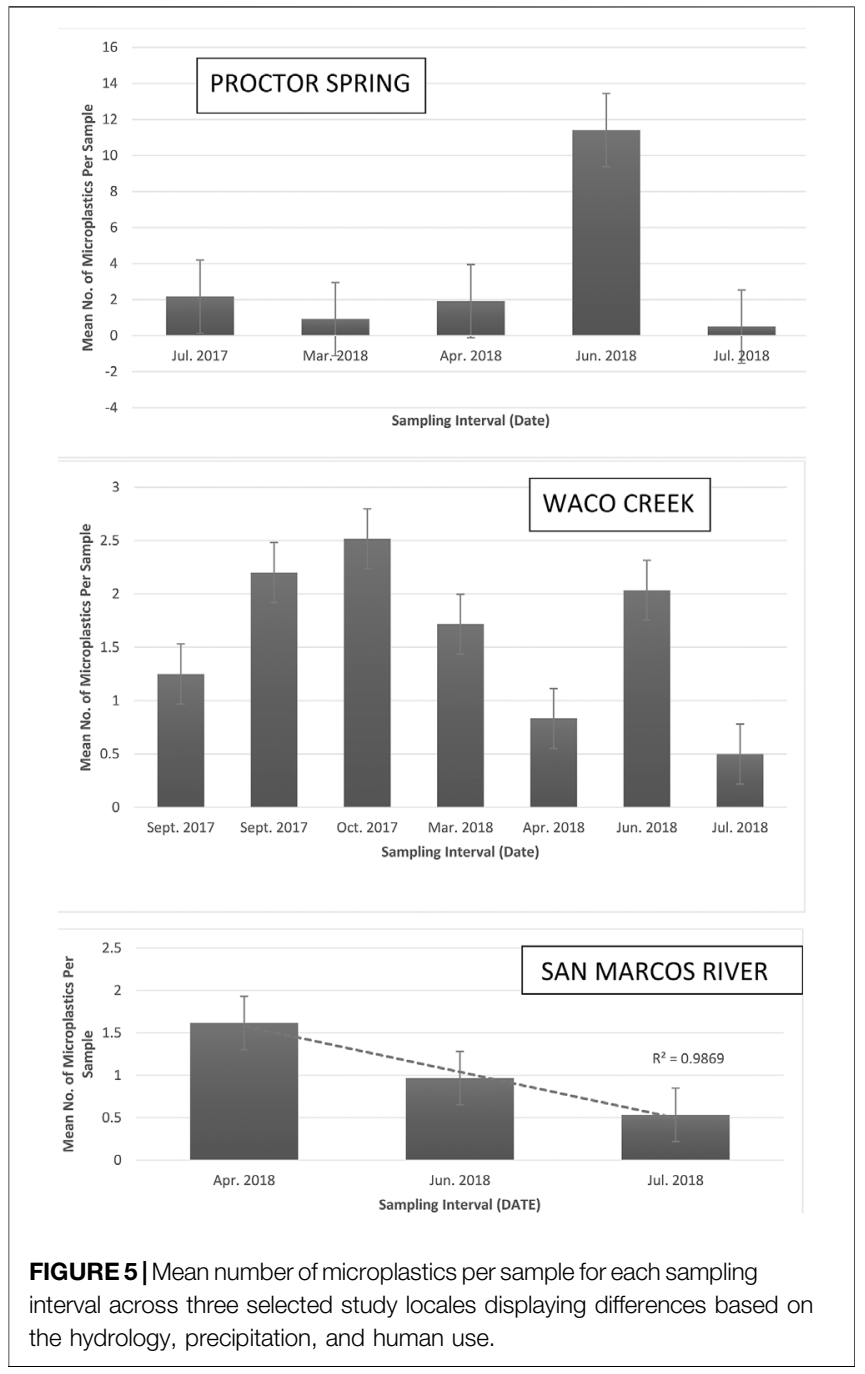

\section{Microplastic Pollution Levels Across a Temporal Scale: A Comparison Between Sampling Intervals}

The overall average microplastic pollution levels differed significantly between sampling intervals $(p=0.000)$ for both Waco Creek and Wilson's Creek. Peak microplastic pollution levels were observed in September and October for Waco Creek and March through June for all other study locales (Figure 5). Conversely, the mean number of microplastics per sample did not differ significantly between sampling intervals for Proctor Springs (PS) $(p=0.060)$, Buena Vista Pond (BV) $(p=0.123)$ and the San Marcos River (SM) $(p=0.055)$.

\section{Microplastic Hue Classification: A Comparison Across Study Locales}

The highest percentage of microplastic particles recovered across all study locales were classified within the transparent and purpleblue hues in color followed by blue, purple, red-purple and red, respectively (Figure 6). Less than ten percent of particles at each

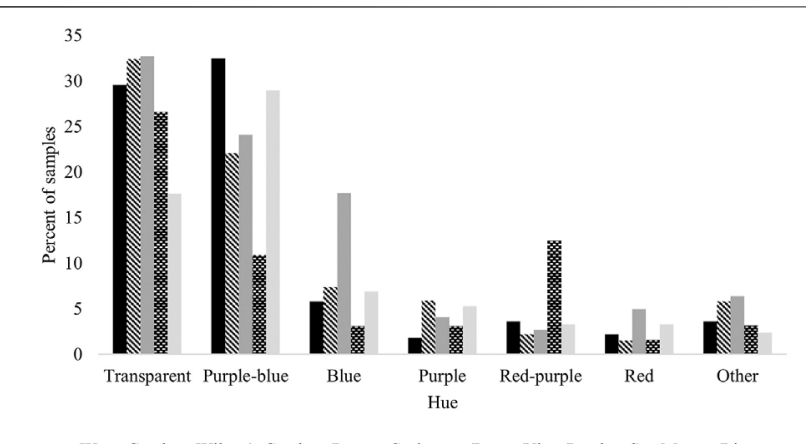

- Waco Creek w Wilson's Creek $₫$ Proctor Springs Buena Vista Pond $₫$ San Marcos River

FIGURE 6 | Microplastic color classification by hue for all study locales.

study locale were classified as "Other", inclusive of yellow-red, yellow, green-yellow, green, blue-green, black, white and iridescent. A color cluster analysis that groups together similarities in microplastic hue by sample site was conducted using the Community Analysis Program III. The resulting dendrogram indicates possible clustering by potential inputs as the upper watershed and springs sample sites are more closely clustered, while the lower watershed and highly urbanized sites are clustered together (Figure 7). The sites higher in recreational use in both the upper and lower segments of the San Marcos River were also closely related. Sample sites with higher mean levels of microplastics, or "hot spots" were found to be similar in hue as well (Figure 7).

\section{DISCUSSION}

Overall, 1,198 microplastics were found, with fibers being the most common particle form (Baldwin et al., 2016; Lin et al., 2018; Baldwin et al., 2020), which is comparable to the results of urban surface water studies conducted by Dris et al. (2015b) and Wang et al. (2017). Differences in microplastic form between study locales may be due to increased road run-off and direct trash input in the more urbanized study locales. The lack of spheres may be due to the absence of industrial discharges or due to differences in the specific gravity of the materials, as this project did not sample the benthos. Positive correlations between microplastic concentration and distance downstream have been previously reported in the literature (Schmidt et al., 2018). Our results, however, did not exhibit such correlations for either the San Marcos River or Waco Creek. These results suggest widespread pollution throughout the urban aquatic systems (Wong et al., 2020), with localized effects of surface run-off and human activity driving subtle changes in microplastic influx levels (Baldwin et al., 2020). Contrasting results between systems such as these regarding the relationship between particle count and location along the stream or river profile have been reported in the literature. For example, in the Rhine River, while the overall pollution levels varied with respect to location, the maximum particle count was observed in the metropolitan area (Mani et al., 2015). These findings are parallel to our results 


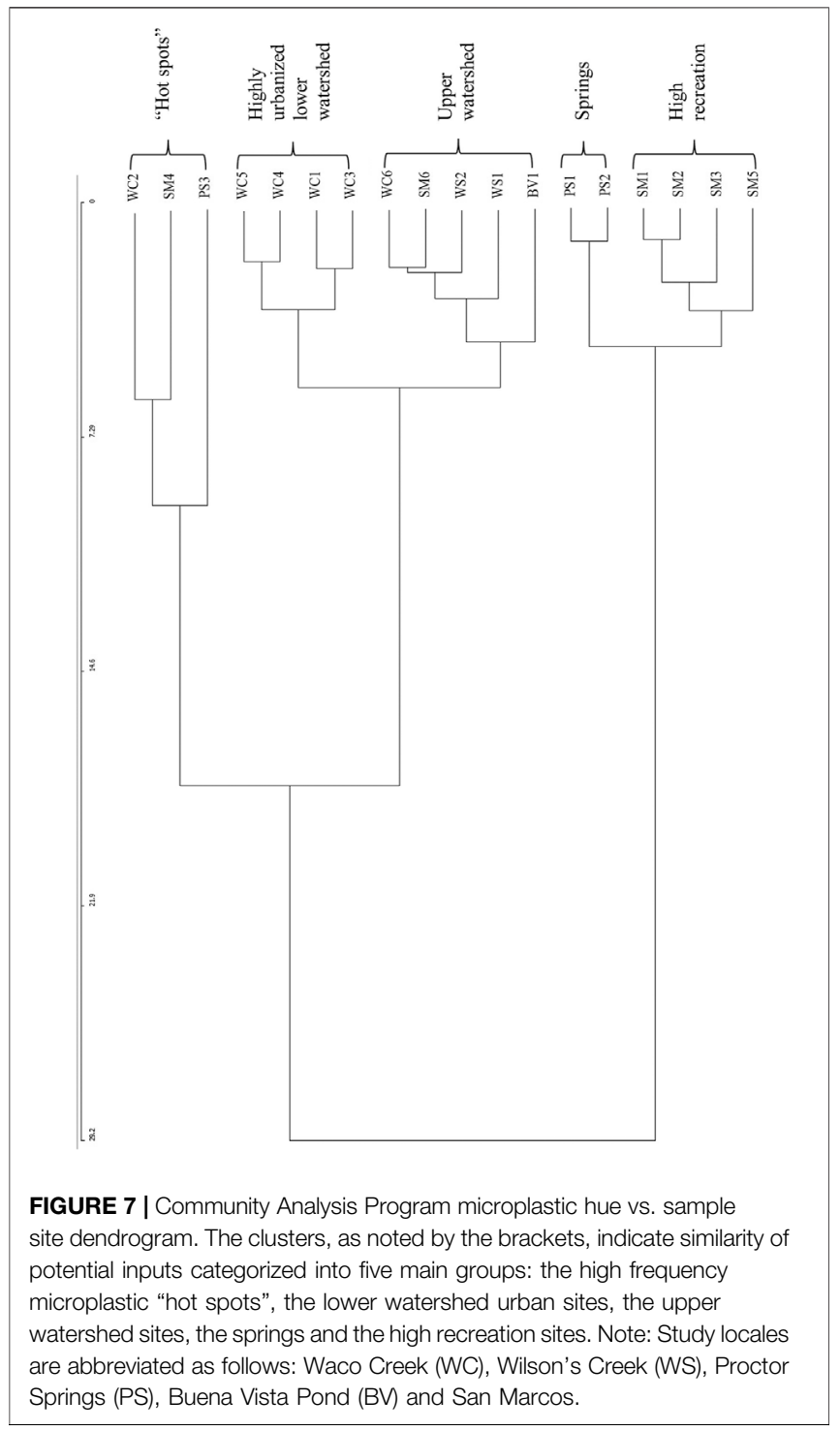

regarding the San Marcos River in that the maximum average particle count along the river was also observed within the city rather than in the more rural land use areas downstream. Baldwin et al. (2020) found that particle counts tended to be higher in areas most subjected to anthropogenic activity. Therefore, the peak in pollution at this point along the river may be explained by the geographical location of the site, a high traffic municipal park and popular site for tubing and canoe launching, as well as the increased levels of concentrated human recreational use and the associated localized, direct influx of trash.

In addition to spatial trends, the observed synchronization between maximum particle counts and seasonal events demonstrates the influence of seasonality on pollution levels across all study locales. These high pollution events are parallel to phenomena that are characteristic of the corresponding seasons such as high run-off during spring rains (March) and increased human recreational use during the summer months (June). Unlike the other study locales, a sizeable stretch of Waco Creek (sites WC1-3) flows in a concrete channel through the heart of Baylor University's campus. Therefore, an increase in the student population and high traffic surrounding campus may be a possible explanation for the high levels observed in Waco Creek during September and October, as this is the time of year when students return to campus and frequent social, sporting, and recreational events occur in and near this area. The significant difference in average microplastic pollution between sampling intervals at Waco Creek and Wilson's Creek suggest that seasonality and localized pulse events may influence short-term fluxes of microplastic levels over time throughout the stream profile. The peak pollution events observed in June, September and October for this study fall within the time frame of May-October, when it is estimated that $75 \%$ of all global riverine plastic inputs into the ocean occur (Lebreton et al., 2017). This seasonal variation is influenced strongly by global rainfall patterns. Specifically, for North American rivers, global models predicted peak microplastic inputs between June and October (Lebreton et al., 2017). Vincent and Hoellein (2021), however, found one of the urban streams in their study had a significantly higher concentration of microplastics in the water column in the fall, while the other two streams investigated displayed no differences by sampling date. The lack of significant patterns in microplastic pollution frequency between micro-habitat types, water types and sample sites across study locales (except for the San Marcos River), failed to support our hypothesis that still water micro-habitats have more microplastics per sample, on average, than running water micro-habitats. Vincent and Hoellein (2021) did find major differences in retention of plastics in urban streams relative to benthic materials, with gravel as a hot spot, while concrete, sand, and cobble retained fewer particles.

In the case of the San Marcos River, significantly higher levels of microplastic pollution in the upper portion of the watershed upstream of the WWTP suggest that localized inputs via sources such as surface run-off and aerial transport (De Falco et al., 2020) may influence microplastic pollution levels in highly urbanized areas that are not receiving sewage discharge. These findings are the opposite of that of the Rhine and Meuse Rivers, where high levels of microplastics were measured in the receiving waters of treated and untreated wastewater (Leslie et al., 2017). The significant differences between sample sites with and without sources of treated wastewater effluent may also be attributed to differences in land use, development, and flow (Chen et al., 2020) for the upper and lower segments of the river. The Aquarena springs discharge a mean flow of 169 cubic feet per second (cfs), which heavily influences the hydrology of the upper segment as its main water source. Primary land and water use include urban, residential, industry, recreation (fishing, swimming, canoeing, and tubing), agricultural and cattle, poultry, and oil production. Two of the three permitted WWTPs are in the upper segment of the river: the city of San Marcos's WWTP [permitted discharge = 9 million gallons per day (mgd)] and the Texas Parks and Wildlife Department's A.E. Wood Fish Hatchery. The upper segment of the river is subjected to substantially higher levels of urbanization and direct contact with humans in comparison to the lower river. The lower segment of the river has a median instantaneous flow of 272 cfs. Primary land and water use include recreation (i.e. swimming, canoeing, and tubing), farm and ranchland. The third permitted WWTP is managed by the city of Luling, TX 
(permitted discharge $=500,000 \mathrm{mgd}$ ) and is in the lower segment of the river downstream of our sampling sites (Guadalupe-Blanco River Authority, 2008). These findings fail to support our hypothesis that sample sites not containing local point source sewage effluent had lower microplastic pollution levels than sample sites with local point source sewage effluent.

A statistical ranking of all five study locales from most to least polluted found Proctor Springs to be the most polluted, while Buena Vista Pond was the least polluted. Despite the use of Buena Vista Pond for recreational fishing, factors such as geographical isolation relative to the other study locales in combination with comparatively lower levels of urbanization and the absence of regular, direct contact with humans (e.g., swimmers, boaters, and tubers) may all be valid explanations as to why it is statistically regarded at the cleanest site, on average, in terms of surface water pollution (Baldwin et al., 2020). These findings support our hypothesis that study locales subjected to high volume human recreational use have higher pollution levels than those that comparatively are not as accessible to direct human contact. In contrast, the statistical ranking fails to support the hypothesis that groundwater and/or spring-fed systems have fewer microplastics per sample, on average, than run-off fed systems as the most polluted locale was a groundwater fed spring. Significantly higher levels of microplastics at Proctor Springs demonstrate the variation in pollution levels between a low discharge spring and the other study locales of varying water sources. However, we are inclined to believe that this difference is more of a result of local land use differences and seasonality (Wong et al., 2020) confounded by concentrated human recreational activity and frequent direct human contact (Baldwin et al., 2020) and less attributed to differences in the actual water source. Further, elevated pollution levels at Proctor Springs may also be attributed to its concrete channelized urbanization (Townsend et al., 2019) in combination with low water volume and a small stream channel area relative to the other locales potentially exhibiting a concentration effect, as previously reported in smaller lakes (Faure et al., 2012; Free et al., 2014). That is, higher levels of plastics being deposited at higher frequencies into lower volumes of water would likely result in more microplastics present per unit volume.

Hot spotting at concentrated human recreational sites and the dendrogram results showing that similar land use type may result in analogous input sources, plastic types and colors (e.g., swimsuits, plastic innertubes, rubber flip flops, etc.) are both findings that support the concept of localized effects being a major influence on the type of materials (Tziourrou et al., 2019). For example, fibers may be more prominent where clothing is a major input, whereas fragments may be more common where there are more weathered plastic items being deposited, such as plastic bottles. High similarity in microplastic hue among the hot spots may be a result of a wider variety of hues recovered in the samples due to a higher particle count.

This study specifically quantified microplastics present in surface water samples only (i.e., buoyant plastics). Plastic materials vary not only in buoyancy, but also in density and sinking rate (Fazey and Ryan, 2016). Therefore, the concentrations reported here may be an underestimate of the total microplastic concentration within each system as higher density plastics below the surface, throughout the water column and settled within the sediment were not directly accounted for. Our sample volume of $800 \mathrm{ml}$ was adequate to detect microplastics and an appropriate volume to collect for consistent samples in shallow streams during the summer months. A follow up project in which the recovered microplastics are chemically analyzed and identified by polymer type via methods such as Fourier-transform infrared spectroscopy (FTIR) or Pyr-GCMS may be beneficial in obtaining more information regarding possible input sources and common plastic types associated with land use type (e.g., recreational, residential, industrial, etc.).

\section{CONCLUSION}

This study investigated the effects of seasonality, type of run-off generation and urbanization on microplastic pollution levels as well as the spatial distribution of microplastics within freshwater systems with and without treated effluent discharge through field sampling and visual analysis of urban surface water samples. Over 1,000 microplastic particles were recovered from 779 samples across five study locales, with the mean number of microplastics per $800 \mathrm{ml}$ sample ranging from $0.98-3.38$ across the five study systems. The presence of wastewater treatment plants upstream was not a primary determinant of microplastic presence or frequency, probably due to the use of advanced methods, such as sand filters, to treat effluent prior to release. Sampling relative to riffles, pools, and the location of stream banks did not indicate major differences in microplastic frequency in surface waters. Overall, the results suggest that seasonality and local human activity have a stronger influence on overall microplastic frequency within the system, while particle color and type vary with the spatial positioning within the watershed and adjacent land use. The results of the study have contributed to the continually growing body of existing knowledge related to microplastic pollution in freshwater systems and have aided in providing a better understanding of the abundance, transport, and origin of microplastics within the urban surface waters of small watershed systems in the central Texas region. The global increase of plastic production and use, in addition to the continued overall mismanagement of waste, further support the conclusion that continued research, effective mitigation practices, governmental attention, and increased public awareness are urgent needs Mathalon and Hill, 2014.

\section{DATA AVAILABILITY STATEMENT}

The raw data supporting the conclusion of this article will be made available by the authors, without undue reservation.

\section{AUTHOR CONTRIBUTIONS}

SB conceived the idea and obtained funding; SB and JS designed research; JS performed research; SB and JS analyzed data; JS 
constructed the figures; JS wrote the manuscript; and SB reviewed and edited manuscript drafts.

\section{FUNDING}

A Baylor University Research Committee grant, a Baylor University Glasscock Grant, and the Department of Environmental Science, Baylor University, Waco, TX, United States, provided funding to support this research project.

\section{REFERENCES}

Allen, S., Allen, D., Phoenix, V. R., Le Roux, G., Jiménez, P. D., Simonneau, A., et al. Author Correction: Atmospheric Transport and Deposition of Microplastics in a Remote Mountain Catchment. Nat. Geosci. (2019) 12:679. doi:10.1038/ s41561-019-0409-4

Andrady, A. L., Microplastics in the marine Environment. Mar. Pollut. Bull. (2011) 62:1596-1605. doi:10.1016/j.marpolbul.2011.05.030

Baldwin, A. K., Corsi, S. R., and Mason, S. A., Plastic Debris in 29 Great Lakes Tributaries: Relations to Watershed Attributes and Hydrology. Environ. Sci. Technol. (2016) 50:10377-10385. doi:10.1021/acs.est.6b02917

Baldwin, A. K., Spanjer, A. R., Rosen, M. R., and Thom, T., Microplastics in Lake Mead National Recreation Area, USA: Occurrence and Biological Uptake. PLoS One (2020) 15:e0228896. doi:10.1371/journal.pone.0228896

Barnes, D. K. A., Galgani, F., Thompson, R. C., and Barlaz, M., Accumulation and Fragmentation of Plastic Debris in Global Environments. Phil. Trans. R. Soc. B (2009) 364:1985-1998. doi:10.1098/rstb.2008.0205

Browne, M. A., Crump, P., Niven, S. J., Teuten, E., Tonkin, A., Galloway, T., et al. Accumulation of Microplastic on Shorelines Woldwide: Sources and Sinks. Environ. Sci. Technol. (2011) 45:9175-9179. doi:10.1021/es201811s

Carr, S. A., Liu, J., and Tesoro, A. G. Transport and Fate of Microplastic Particles in Wastewater Treatment Plants. Water Res. (2016) 91:174-182. doi:10.1016/j. watres.2016.01.002

Chen, H., Jia, Q., Zhao, X., Li, L., Nie, Y., Liu, H., et al. The Occurrence of Microplastics in Water Bodies in Urban Agglomerations: Impacts of Drainage System Overflow in Wet Weather, Catchment Land-Uses, and Environmental Management Practices. Water Res. (2020) 183:116073. doi:10.1016/j.watres. 2020.116073

Dalu, T., Banda, T., Mutshekwa, T., Munyai, L. F., and Cuthbert, R. N., Effects of Urbanisation and a Wastewater Treatment Plant on Microplastic Densities along a Subtropical River System. Environ. Sci. Pollut. Res. (2021) 28(7): 36102-36111. doi:10.1007/s11356-021-13185-1

De Falco, F., Gullo, M. P., Gentile, G., Di Pace, E., Cocca, M., Gelabert, L., et al. Evaluation of Microplastic Release Caused by Textile Washing Processes of Synthetic Fabrics. Environ. Pollut. (2018) 236:916-925. doi:10.1016/j.envpol. 2017.10.057

De Falco, F., Cocca, M., Avella, M., and Thompson, R. C., Microfiber Release to Water, via Laundering, and to Air, via Everyday Use: A Comparison between Polyester Clothing with Differing Textile Parameters. Environ. Sci. Technol. (2020) 54:3288-3296. doi:10.1021/acs.est.9b06892

Di, M., and Wang, J., Microplastics in Surface Waters and Sediments of the Three Gorges Reservoir, China. Sci. Total Environ. (2018) 616-617:1620-1627. doi:10. 1016/j.scitotenv.2017.10.150

Dris, R., Imhof, H., Sanchez, W., Gasperi, J., Galgani, F., Tassin, B., et al. Beyond the Ocean: Contamination of Freshwater Ecosystems with (Micro-)plastic Particles. Environ. Chem. (2015a) 12:539. doi:10.1071/EN14172

Dris, R., Gasperi, J., Rocher, V., Saad, M., Renault, N., and Tassin, B., Microplastic Contamination in an Urban Area: a Case Study in Greater Paris. Environ. Chem. (2015b) 12:592-599. doi:10.1071/EN14167

Eerkes-Medrano, D., Thompson, R. C., and Aldridge, D. C., Microplastics in Freshwater Systems: A Review of the Emerging Threats, Identification of

\section{ACKNOWLEDGMENTS}

The authors thank Jessica Bateman, Hannah Dye, Lauren Medlin, Madison Ohler, Jonah Salazar, Rafael Sandoval, and Jordan Vanderpool for their assistance with field work and sample analysis. The authors thank Dr. Erica D. Bruce and Dr. Joe C. Yelderman, Jr. for their service as thesis committee members. The authors also thank Tom Goynes, property owner of the San Marcos River Retreat, for providing access to the river for sample collection and Ashley Nystrom of the City of Waco Water Department for providing the site map of Waco Creek.

Knowledge Gaps and Prioritisation of Research Needs. Water Res. (2015) 75:63-82. doi:10.1016/j.watres.2015.02.012

Faure, F., Corbaz, M., Baecher, H., and de Alencastro, L. F., Pollution Due to Plastics and Microplastics in Lake Geneva and in the Mediterranean Sea. Arch. Sci. (2012) 65:157-164.

Fazey, F. M. C., and Ryan, P. G., Biofouling on Buoyant marine Plastics: An Experimental Study into the Effect of Size on Surface Longevity. Environ. Pollut. (2016) 210:354-360. doi:10.1016/j.envpol.2016.01.026

Free, C. M., Jensen, O. P., Mason, S. A., Eriksen, M., Williamson, N. J., and Boldgiv, B., High-levels of Microplastic Pollution in a Large, Remote, mountain lake. Mar. Pollut. Bull. (2014) 85:156-163. doi:10.1016/j. marpolbul.2014.06.001

Geyer, R., Jambeck, J. R., and Law, K. L., Production, Use, and Fate of All Plastics Ever Made. Sci. Adv. (2017) 3:e1700782. doi:10.1126/sciadv.1700782

Guadalupe-Blanco River Authority. San Marcos 2008 Basin Summary Report (2008). Available from: https://www.gbra.org/documents/publications/ basinsummary/2008h.pdf (Accessed June 15, 2018).

Hendrickson, E., Minor, E. C., and Schreiner, K., Microplastic Abundance and Composition in Western Lake Superior as Determined via Microscopy, PyrGC/MS, and FTIR. Environ. Sci. Tech. (2018) 52(4):1787-1796. doi:10.1021/acs. est.7b05829

Hidalgo-Ruz, V., Gutow, L., Thompson, R. C., and Thiel, M., Microplastics in the marine Environment: a Review of the Methods Used for Identification and Quantification. Environ. Sci. Technol. (2012) 46:3060-3075. doi:10.1021/ es2031505

Ivar do Sul, J. A., and Costa, M. F., The Present and Future of Microplastic Pollution in the marine Environment. Environ. Pollut. (2014) 185:352-364. doi:10.1016/j.envpol.2013.10.036

Jambeck, J. R., Geyer, R., Wilcox, C., Siegler, T. R., Perryman, M., Andrady, A., et al. Plastic Waste Inputs from Land into the Ocean. Science (2015) 347:768-771. doi:10.1126/science.1260352

Jiang, C., Yin, L., Wen, X., Du, C., Wu, L., Long, Y., et al. Microplastics in Sediment and Surface Water of West Dongting lake and South Dongting lake: Abundance, Source and Composition. Int. J. Environ. Res. Public Health (2018) 15:2164. doi:10.3390/ijerph15102164

Kapp, K. J., and Yeatman, E., Microplastic Hotspots in the Snake and Lower Columbia Rivers: a Journey from the Greater Yellowstone Ecosystem to the Pacific Ocean. Environ. Pollut. (2018) 241:1082-1090. doi:10.1016/j.envpol. 2018.06.033

Lahens, L., Strady, E., Kieu-Le, T.-C., Dris, R., Boukerma, K., Rinnert, E., et al. Macroplastic and Microplastic Contamination Assessment of a Tropical River (Saigon River, Vietnam) Transversed by a Developing Megacity. Environ. Pollut. (2018) 236:661-671. doi:10.1016/j.envpol.2018.02.005

Law, K. L., and Thompson, R. C., Microplastics in the Seas. Science (2014) 345: 144-145. doi:10.1126/science.1254065

Lebreton, L. C. M., Van Der Zwet, J., Damsteeg, J.-W., Slat, B., Andrady, A., and Reisser, J., River Plastic Emissions to the World's Oceans. Nat. Commun. (2017) 8:1-10. doi:10.1038/ncomms15611

Leslie, H. A., Brandsma, S. H., van Velzen, M. J. M., and Vethaak, A. D., Microplastics en route: Field measurements in the Dutch river delta and Amsterdam canals, wastewater treatment plants, North Sea sediments and biota. Environ. Int. (2017) 101:133-142. doi:10.1016/j.envint.2017.01.018 
Li, C., Busquets, R., and Campos, L. C., Assessment of Microplastics in Freshwater Systems: A Review. Sci. Total Environ. (2020) 707:135578. doi:10.1016/j. scitotenv.2019.135578

Lin, L., Zuo, L.-Z., Peng, J.-P., Cai, L.-Q., Fok, L., Yan, Y., et al. Occurrence and Distribution of Microplastics in an Urban River: A Case Study in the Pearl River along Guangzhou City, China. Sci. Total Environ. (2018) 644:375-381. doi:10. 1016/j.scitotenv.2018.06.327

Mani, T., Hauk, A., Walter, U., and Burkhardt-Holm, P., Microplastics Profile along the Rhine River. Sci. Rep. (2015) 5:17988. doi:10.1038/srep17988

Mason, S. A., Garneau, D., Sutton, R., Chu, Y., Ehmann, K., Barnes, J., et al. Microplastic Pollution Is Widely Detected in US Municipal Wastewater Treatment Plant Effluent. Environ. Pollut. (2016) 218:1045-1054. doi:10. 1016/j.envpol.2016.08.056

Masura, J., Baker, J., Foster, G., Arthur, C., and Herring, C., Laboratory Methods for the Analysis of Microplastics in the marine Environment: Recommendations for Quantifying Synthetic Particles in Waters and Sediments. Silver Spring, MD: NOAA. Technical Memorandum NOS-OR\&R-48 (2015).

Mathalon, A., and Hill, P., Microplastic Fibers in the Intertidal Ecosystem Surrounding Halifax Harbor, Nova Scotia. Mar. Pollut. Bull. (2014) 81: 69-79. doi:10.1016/j.marpolbul.2014.02.018

Meijer, L. J. J., van Emmerk, T., van der Ent, R., Schmidt, C., and Lebreton, L., More Than 1000 Rivers Account for $80 \%$ of Global Riverine Plastic Emissions into the Ocean. Sci. Advan. (2021) 7:18. doi:10.1126/sciadv.aaz5803

Napper, I. E., and Thompson, R. C., Release of Synthetic Microplastic Plastic Fibres from Domestic Washing Machines: Effects of Fabric Type and Washing Conditions. Mar. Pollut. Bull. (2016) 112:39-45. doi:10.1016/j.marpolbul. 2016.09.025

Noseworthy, C., O'Rielly, C., Perry, W. L., and Rowley, R. J., Watershed Characteristics Affect Microplastic Concentrations in a central Illinois Urban Stream. Abstracts with Programs. Geol. Soc. Am. (2021) 53 (3), 12-3. doi:10.1130/abs/2021NC-36285

Peeken, I., Primpke, S., Beyer, B., Gütermann, J., Katlein, C., Krumpen, T., et al. Arctic Sea Ice Is an Important Temporal Sink and Means of Transport for Microplastic. Nat. Commun. (2018) 9:1505-1512. doi:10.1038/s41467-01803825-5

Peng, G., Xu, P., Zhu, B., Bai, M., and Li, D., Microplastics in Freshwater River Sediments in Shanghai, China: A Case Study of Risk Assessment in MegaCities. Environ. Pollut. (2018) 234:448-456. doi:10.1016/j.envpol.2017.11.034

Peters, C. A., and Bratton, S. P., Urbanization Is a Major Influence on Microplastic Ingestion by Sunfish in the Brazos River basin, central Texas, USA. Environ. Pollut. (2016) 210:380-387. doi:10.1016/j.envpol.2016.01.018

Peters, C. A., Thomas, P. A., Rieper, K. B., and Bratton, S. P., Foraging Preferences Influence Microplastic Ingestion by Six marine Fish Species from the Texas Gulf Coast. Mar. Pollut. Bull. (2017) 124:82-88. doi:10.1016/j.marpolbul.2017. 06.080

Peters, C. A., Hendrickson, E., Minor, E. C., Schreiner, K., Halbur, J., and Bratton, S. P., Pyr-GC/MS Analysis of Microplastics Extracted from the Stomach Content of Benthivore Fish from the Texas Gulf Coast. Mar. Pollut. Bull. (2018) 137:91-95. doi:10.1016/j.marpolbul.2018.09.049

Schmidt, L. K., Bochow, M., Imhof, H. K., and Oswald, S. E., Multi-temporal Surveys for Microplastic Particles Enabled by a Novel and Fast Application of SWIR Imaging Spectroscopy - Study of an Urban Watercourse Traversing the City of Berlin, Germany. Environ. Pollut. (2018) 239:579-589. doi:10.1016/j. envpol.2018.03.097
Sighicelli, M., Pietrelli, L., Lecce, F., Iannilli, V., Falconieri, M., Coscia, L., et al. Microplastic Pollution in the Surface Waters of Italian Subalpine Lakes. Environ. Pollut. (2018) 236:645-651. doi:10.1016/j.envpol.2018.02.008

Simon, M., van Alst, N., and Vollertsen, J., Quantification of Microplastic Mass and Removal Rates at Wastewater Treatment Plants Applying Focal Plane Array (FPA)-based Fourier Transform Infrared (FT-IR) Imaging. Water Res. (2018) 142:1-9. doi:10.1016/j.watres.2018.05.019

Talbot, R., and Chang, H., Microplastics in Freshwater: A Global Review of Factors Affecting Spatial and Temporal Variations. Environ. Pollut. (2022) 292:118393. Part B. doi:10.1016/j.envpol.2021.118393

Thiel, M., Hinojosa, I. A., Miranda, L., Pantoja, J. F., Rivadeneira, M. M., and Vásquez, N., Anthropogenic marine Debris in the Coastal Environment: A Multi-Year Comparison between Coastal Waters and Local Shores. Mar. Pollut. Bull. (2013) 71:307-316. doi:10.1016/j.marpolbul.2013.01.005

Townsend, K. R., Lu, H.-C., Sharley, D. J., and Pettigrove, V., Associations between Microplastic Pollution and Land Use in Urban Wetland Sediments. Environ. Sci. Pollut. Res. (2019) 26:22551-22561. doi:10.1007/s11356-019-04885-w

Tziourrou, P., Megalovasilis, P., Tsounia, M., and Karapanagioti, H. K., Characteristics of Microplastics on Two Beaches Affected by Different Land Uses in Salamina Island in Saronikos Gulf, East Mediterranean. Mar. Pollut. Bull. (2019) 149:110531. doi:10.1016/j.marpolbul.2019.110531

Vincent, A. E. S., and Hoellein, T. J., Distribution and Transport of Microplastic and fine Particulate Organic Matter in Urban Streams. Ecol. Appl. (2021) 31:8. e02429. doi:10.1002/eap.2429

Wang, W., Ndungu, A. W., Li, Z., and Wang, J., Microplastics Pollution in Inland Freshwaters of China: a Case Study in Urban Surface Waters of Wuhan, China. Sci. Total Environ. (2017) 575:1369-1374. doi:10.1016/j.scitotenv.2016.09.213

Wang, W., Yuan, W., Chen, Y., Wang, J., and Wang, W., Microplastics in Surface Waters of Dongting Lake and Hong Lake, China. Sci. Total Environ. (2018) 633: 539-545. doi:10.1016/j.scitotenv.2018.03.211

Wong, G., Löwemark, L., and Kunz, A., Microplastic Pollution of the Tamsui River and its Tributaries in Northern Taiwan: Spatial Heterogeneity and Correlation with Precipitation. Environ. Pollut. (2020) 260:113935. doi:10.1016/j.envpol. 2020.113935

Yin, L., Jiang, C., Wen, X., Du, C., Zhong, W., Feng, Z., et al. Microplastic Pollution in Surface Water of Urban Lakes in Changsha, China. Int. J. Environ. Res. Public Health (2019) 16:1650. doi:10.3390/ijerph16091650

Conflict of Interest: The authors declare that the research was conducted in the absence of any commercial or financial relationships that could be construed as a potential conflict of interest.

Publisher's Note: All claims expressed in this article are solely those of the authors and do not necessarily represent those of their affiliated organizations, or those of the publisher, the editors, and the reviewers. Any product that may be evaluated in this article, or claim that may be made by its manufacturer, is not guaranteed or endorsed by the publisher.

Copyright $\odot 2022$ Stovall and Bratton. This is an open-access article distributed under the terms of the Creative Commons Attribution License (CC BY). The use, distribution or reproduction in other forums is permitted, provided the original author(s) and the copyright owner(s) are credited and that the original publication in this journal is cited, in accordance with accepted academic practice. No use, distribution or reproduction is permitted which does not comply with these terms. 